\title{
Biodiversity of the marine environment around Ascension Island, South Atlantic
}

\section{INTRODUCTION}

We are pleased to present this Special Issue of JMBA, which charts the major results from the Darwin Challenge Award (Assessing Ascension Islands Shallow Marine Biodiversity. EIDCF012). Research presented in this issue is the result of three expeditions that could not have been achieved without a great deal of collaborative support from many organizations.

Ascension Island harbours globally important biodiversity, representing a unique assemblage of western and eastern Atlantic flora and fauna. Previous biodiversity projects have focused on sea turtles, seabirds and plants, whist marine biodiversity was virtually unknown; a search on Google Scholar and Web of Science at that time indicated few if any collective studies on the Island's benthic species, habitats or biogeography. Lacking were comprehensive inventories of marine invertebrates including corals, ichthyofauna and algae. Habitat inventories and mapping were needed to manage coastal zones.

In total, this body of research accounts for one of the largest coordinated and integrated efforts to provide baseline marine data feeding into the biodiversity and fisheries targets of this UK Overseas Territory. We hope that this Special issue offers a collection of knowledge, experience and guidance for working in this special territory.

\section{PERCEIVED NEEDSIN ASCENSION ISLAND}

Ascension is $\sim 1600 \mathrm{~km}$ from the coast of West Africa and more than $2000 \mathrm{~km}$ from South America, and it is one of the most remote land bodies in the world. This isolation, combined with Ascension's comparative geological youth $\left(\sim_{1}\right.$ million years old) (Evangelidis et al., 2004), is thought to have in part contributed to a relatively depauperate shallow marine fauna. For example, there are just 173 inshore fish species recorded to date compared with over 300 fish species in other tropical Atlantic Islands (Wirtz et al., 2017). However, while there is low fish species richness there is also high species abundance and a relatively high level of endemism (Lubbock, 1980; Floeter et al., 2008), with 11 species $(8.3 \%$ of total) known only from Ascension, and a further 16 (12\% of total) restricted to the South Atlantic islands of Ascension and St Helena (Wirtz et al., 2017). This fish assemblage represents a unique mix of species from both the western and eastern Atlantic (Floeter et al., 2008), and this knowledge has provided part of the evidence basis for the Island being nominated, in September 2016, as part of a large Marine Protected Area (Foreign \& Commonwealth Office, 2016).

The following important works formed much of the background for our expeditions: Chace \& Manning (1972), Manning \& Chace (1990) (Crustacea), Rosewater (1975) (Mollusca), Hartmann-Schroder (1992) (Polychaeta), and Price \& John $(1979,1980)$ (marine flora). A representative list of the older visiting expeditions and corresponding literature can be found in Manning \& Chace (1990).

Species and habitat inventories and mapping were recognized as being urgently needed to manage coastal zones. In 2012 the Ascension Island Government (AIG) and the University of Exeter (UoE) were awarded a Darwin grant to develop the first National Biodiversity Action Plan for Ascension Island, integrating all available information on the spatial distribution of biodiversity and threats. However, with the exception of seabirds and marine turtles, the BAP project had a predominantly terrestrial focus, in large part due to the current paucity of baseline scientific data for marine species that was needed to inform the development of Species Action Plans.

\section{TIMELINE AND LOGISTICS - DARWININITIATIVE SURVEYS [2012/13]}

In 2012 the Shallow Marine Surveys Group (SMSG), in collaboration with the South Atlantic Environmental Research Institute (SAERI) and supported in kind by the Falkland Islands Government Fisheries Department, was awarded a Darwin Initiative Overseas Territories Challenge Fund award. This enabled the two organizations, with a team of international scientists, in conjunction with Ascension Island Government (AIG) staff, to address some of these issues by generating a great deal of much needed baseline data. Further, this created scope for future marine biodiversity conservation and management actions and projects on the 
Island. The group trained local divers and conservation professionals in sampling protocols such that the collection of baseline data and monitoring of key marine flora and fauna could continue.

Stage One of the work, conducted by British Antarctic Survey (BAS) included a meta-analysis of existing information on Ascension Island marine biodiversity to establish literature and a georeferenced database. Stage Two and Stage Three of the work comprised two surveys where SMSG/ SAERI assembled a team of 24 local and international ecologists, taxonomists and divers for the first survey and 12 ecologists and divers for the second survey. Many of the team had worked successfully together previously as project partners in the UK Overseas Territories of the Falkland Islands and South Georgia \& the South Sandwich Islands. Two members of the team were allocated the responsibility for logistics coordination. This was key to success as their primary focus was on moving people and equipment in support of the project. Both working for the Ministry of Defence (British Forces South Atlantic Islands), one a senior logistics officer, was a direct benefit to the project for their understanding of the military supply chain, which ensured the seamless movement of equipment and people. Preplanning started $\sim_{3}$ months prior to both the main expedition in August 2012 and the follow-up visit in May 2013. Key during the initial planning phase was to identify equipment and stores that could not be procured or obtained in the Falklands or Ascension Island, such as ethanol, camera spares, waterproof paper, additional transact reels, writing boards and specimen containers. The early ordering of equipment allowed for contingency planning if it could not be transported via air, instead giving time to have it transported by ship in order to be in situ in Ascension ahead of each visit.

Freight from the Falklands was booked on the South Atlantic air-bridge through Mount Pleasant Military Base in the Falklands. The expedition had to be self-contained so the freight included diving cylinders, dive equipment and weights, SLR cameras, housings, strobes and medical oxygen as there are no facilities to hire equipment on Ascension. The civilian diving club in Ascension were able to offer compressed air and boats for transit to the dive sites. Seats on the RAF Atlantic Air Bridge had to be booked well in advance due to the limited number of places available for civilian passengers. Accommodation on Ascension Island is very limited, particularly for large groups, so early booking was essential. The first visit comprised a mix of government housing and military accommodation. Access to the military base was not available on the second visit so hotel accommodation was utilized. The Ascension Island Conservation Department was able to offer office space for kit storage, specimen and data processing. Daily planning meetings were held to ensure everyone was in the right place at the right times with transport coordinated to undertake the tasks. Hire cars were booked in advance as vehicle availability is limited and the demand is high with $4 \times 4$ pickups at a premium. The pickups were essential for carrying diving and other equipment to the survey locations. Well planned and delivered logistic support proved to be critical to the success of the project; forward planning, provisioning and an understanding of the limitations of air-freight capacity was essential.
The basis of Stage Two, conducted in September 2012, was an ambitious 3 -week ( 21 day) expedition to the Island to survey the intertidal and sub-tidal zones down to $30 \mathrm{~m}$ depth. We adapted successful protocols from our previous work (quantitative photo-quadrats, collections, macrophotography) and employed established methods specific to coral reef habitats (Underwater Visual Census and quadrat photography), which are proven to be statistically robust and comparative across similar studies carried out in other reef habitats globally (Edgar et al., 1997). In addition to biodiversity and fishery assessment, was a climate change related experiment where expertise from BAS was part of the team; thermal tolerance experiments were conducted to assess the temperature sensitivity of shallow water marine invertebrates at Ascension Island to evaluate their long-term sensitivity to climate warming. Other new areas of research were explored based on observations in Stage One by two phycologists, from the University of Aberdeen and the Hellenic Centre for Marine Research, who assessed and captured as much of Ascension's diversity in terms of seaweeds (macroalgae) as possible during this expedition. Further objectives for Stage Two included examining hard structures from fish (otoliths) and molluscs (shells) in collaboration with the Falkland Islands Fisheries Department, to determine age and growth patterns between and within species and also to look for patterns that could be monitored for climate change.

Other studies included an investigation of biology of the Sally lightfoot crab, Grapsus adscensionis, which were carried out around English Bay and Turtle pond areas, as well as a single sample taken at Catherine Bay. Octopus behaviour (Octopus insularis) was also examined particularly with regards to its diet spectrum. Intertidal surveys were conducted to examine zonation and to examine the diversity of some of the more permanent rock pools. Although this work did not result in published work in this special issue, it did provide useful baseline observations for the first time, that AIG can build on in the future.

The Group deployed settlement plates with attached temperature loggers, with controls, with the aim of monitoring recruitment, succession and growth of encrusting organisms over time and space. The plates are also useful for monitoring for potential invasive species. Very little grows (especially macroalgae) on the surface of rocks at Ascension as the black trigger fish (Melichthys niger) eats almost anything that is exposed. The panels, therefore, needed to be fixed to a solid surface and caged such that trigger fish and other fish grazers could not get access to the underside of the plates.

The second survey, Stage Three, was conducted in May/June 2013. This survey was not planned originally, but unexpected significant saving was made on air fares in our earlier expeditions. This saving allowed for a follow-up trip in May 2013. Our team of 12 started to arrive on 24 May. The objective of this 10-day survey was to build on the first by targeting the intertidal quantitatively, revisiting sites surveyed before to examine temporal patterns for the community structure of different habitats and to visit sites and areas not surveyed previously.

Samples from each survey have been distributed to taxonomic specialists for further examination and confirmation. This work is yielding great results including many new geographic records and some new species. 
The work was successful and surpassed expectation, but was not without problems. The lesson learned was largely based on good daily communication and organization of the wide range of projects and specialist interest that comprised the expedition team. Regular planning meetings and a central data repository were quickly established which resulted in smooth operation.

The diving conditions and the charter of local vessels made shore and further afield dive expeditions relatively easy but the south coast remained unsurveyed due its exposure to the prevailing wind and current.

\section{DUTCOMES}

During the two surveys (Stages Two and Three) a total of 202 sampling events were conducted comprising a mixture of quantitative SCUBA surveys involving belt transects for fish and mobile fauna and quadrat photography for sessile fauna. Intertidal surveys and collections and subtidal collections were also carried out. Oceanographic surveys were conducted around the island. The marine environment is visually dominated by fish, particularly by one species, the black trigger fish. The reefs are heavily grazed and predated by fish to such an extent that a significant component of the biodiversity remains hidden to avoid this pressure. A primary goal was to catalogue such inconspicuous diversity; we found a surprisingly high diversity that has been particularly poorly documented in the past with much of this work still ongoing. The surveys yielded many new geographic records and some new species reported on in this Special Issue. Taxonomic samples are still being worked up and will be reported on in other issues and journals.

Eighteen papers are presented in this issue, and two additional papers resulting from these expeditions were published in earlier issues of JMBA; one of these, Brewin et al. (2016), quantifies the diurnal variation of fish and macrobenthic community structure at Ascension Island. This study revealed significant turnover in species between day and night surveys and between survey periods (2012 vs 2013), with associated changes in species rank-abundance distributions. A number of juvenile fish species were determinate in observed differences. Conversely, diversity of functional groups between day/ night surveys and between seasons were not different. There was, however, significant species turnover within functional groups between day and night assemblages. The lack of proportional change in functional groups but a turn-over of species between day and night assemblages suggest that there may be a degree of functional redundancy in Ascension Island's marine trophic profile. The second, Morely et al. (2016), investigated experimentally, the upper temperature limits of species from different regions, at different rates of warming, to estimate the long-term sensitivity of shallow marine fauna from four tropical Ascension Island, five temperate New Zealand and six Antarctic species. Specifically for Ascension Island, despite being subject to upwelling, results suggest that the fauna have evolved sufficient plasticity to respond to rapid increases in temperature and this will be a key mechanism underpinning vulnerability to climate warming. Finally,
Yáñez-Rivera \& Brown (2015) characterized two species of fireworms from Ascension and Saint Helena.

\section{IMPACT AND FUTURE CONSIDERATIONS}

The preliminary results of the Challenge Award and indeed discussions with collaborators and scientists, internationally and on Ascension, was the genesis for the full Darwin Plus Project - The Ascension Island Marine Sustainability Project (AIMS). Through this award, critical laboratory and equipment infrastructure was purchased for AIG. This 2-year project will be presenting its findings in a variety of journals over the next months and years. Indeed this issue contains one paper from the AIMS project that reports and describes the deeper water environments around Ascension Island.

As editors we hope that more comparative studies will ensue on subjects surrounding the biological connectivity of tropical eastern and western Atlantic environments to those in the mid-Atlantic, notably Ascension and St Helena.

\section{ACKNDWLEDGEMENTS AND FINANCIAL SUPPDRT}

Funding for this work came from a grant to the Shallow Marine Surveys Group (SMSG) from the Darwin Initiative (EIDCFo12). The two expeditions were organized by SMSG and the South Atlantic Environmental Research Institute (SAERI). The Editors thank the volunteer members of SMSG for excellent work in the field, and the continued support of the Falkland Island Government Fisheries Department. We would also like to thank the Ascension Island Government, the staff at the Conservation Centre particularly Nick and Sam Weber, and the Ascension Island Dive Club for their logistical support, cooperation, accommodation and hospitality. We are very grateful to British Forces South Atlantic Islands for their logistical support. Furthermore, we would like to thank the Blue Marine Foundation in association with a Darwin Initiative Grant (DPLUSo21), the National Environment Research Council (NERC), BAS for enabling the very successful deep water survey around Ascension in October 2015.

Finally we are extremely grateful for the following people who participated in the coastal fieldwork for the Darwin Challenge Award: Sam Weber (Ascension Island Government), Nicola Weber (Ascension Island Government), Martin Collins (SMSG), Stephen Cartwright (SMSG), Wetjens Dimmlich (SMSG), Steve Brown (SMSG), Dion Poncet (SMSG), Juliet Hennequin (SMSG), Vladimir Laptikhovsky (SMSG), Lt Col. Simon Browning (British Forces South Atlantic Islands/SMSG), Sarah Browning (SMSG), Jerry Pierce (SMSG), Simon Morley (British Antarctic Survey), Alexander Arkhikpin (Falkland Islands Government Fisheries Department), Zhanna Shcherbich (Falkland Islands Government Fisheries Department), Peter Wirtz (Universidade do Algarve), Konstantinos Tsiamis (Hellenic Centre for Marine Research), Pieter van West (University of 
Aberdeen), Caz Young (Ascension Island Dive Club), and Jimmy Young (George Town, Ascension Island).
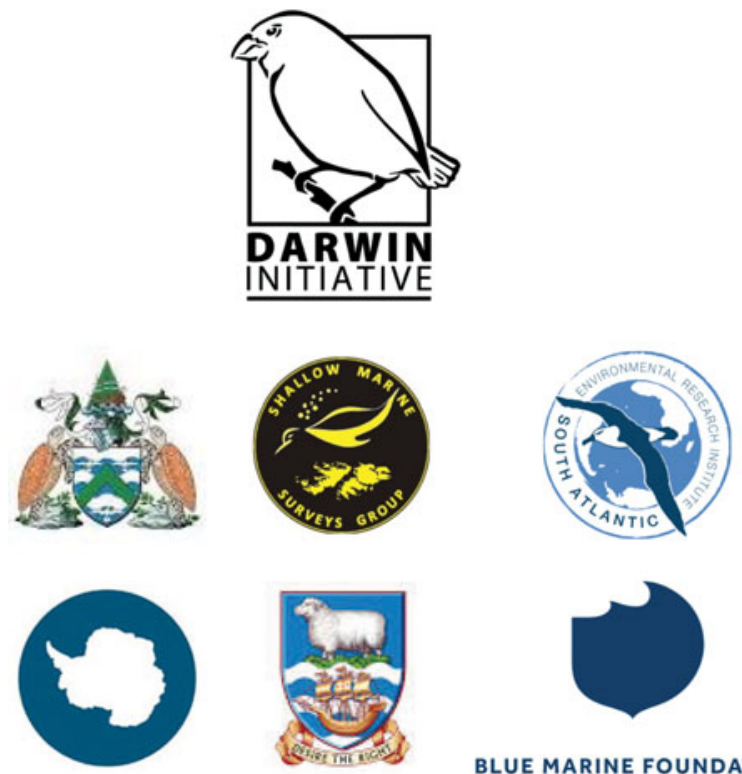

BLUE MARINE FOUNDATION

\section{REFERENCES}

Brewin P.E., Brown J. and Brickle P. (2016) Diurnal variation of fish and macrobenthic invertebrate community structure in an isolated oceanic island of the South Atlantic. Journal of the Marine Biological Association of the United Kingdom 96, 737-747.

Chace F.A. Jr and Manning R.B. (1972) Two new caridean shrimps, one representing a new family, from marine pools on Ascension Island (Crustacea: Decapoda: Natantia). Smithsonian Contributions to Zoology 131, 1-18.

Edgar G.J., Moverley J., Barrett N.S., Peters D. and Reed C. (1997) The conservation-related benefits of a systematic marine biological sampling programme: the Tasmanian reef bioregionalisation as a case study. Biological Conservation 79, 227-240.

Evangelidis C.P., Minshull T.A. and Henstock T.J. (2004) Three-dimensional crustal structure of Ascension Island from active source seismic tomography. Geophysical Journal International 159, 311-325.

Floeter S.R., Rocha L.A., Robertson D.R., Joyeux J.C., Smith-Vaniz W.F., Wirtz P., Edwards A.J., Barreiros J.P., Ferreira C.E.L., Gasparini J.L., Brito A., Falcón J.M., Bowen B.W. and Bernardi G. (2008) Atlantic reef fish biogeography and evolution. Journal of Biogeography 35, 22-47.

Foreign \& Commonwealth Office (2016) Press release: UK set to protect 4 million square kilometres of ocean. https://www.gov.uk/ government/news/uk-set-to-protect-four-million-square-kilometresof-ocean (accessed 16 October 2016).

Hartmann-Schroder G. (1992) Die polychaeten der AmsterdamExpedition nach der Insel Ascension (Zentral-Atlantik). Bijdragen tot de Dierkunde 61, 219-235.

Lubbock R. (1980) The shore fishes of Ascension Island. Journal of Fish Biology 17, 283-303.

Manning R.B. and Chace F.A. Jr (1990) Decapod and Stomatopod Crustacea from Ascension Island, South Atlantic Ocean). Smithsonian Contributions to Zoology 503, 1-104.

Morely S.A., Bates A.E., Lamare M., Nguyen K.D., Brown J. and Peck L.S. (2016) Rates of warming and the global sensitivity of shallow water marine invertebrates to elevated temperature. Journal of the Marine Biological Association of the United Kingdom 96, 159-165.

Price J.H. and John D.M. (1979) Subtidal ecology in Antigua and Ascension. Progress in Underwater Science, New Series 3, 111-133.

Price J.H. and John D.M. (1980) Ascension Island, South Atlantic: a survey of inshore benthic macroorganisms, communities and interactions. Aquatic Botany 9, 251-278.

Roeswater J. (1975) An annotated list of the Marine Mollusks of Ascension Island, South Atlantic Ocean. Smithsonian Contributions to Zoology 503, 1-52.

Wirtz P., Bingeman J., Bingeman J., Frickle R., Hook T.J. and Young J. (2017) The fishes of Ascension Island, central Atlantic Ocean - new records and an annotated checklist. Journal of the Marine Biological Association of the United Kingdom 97, 783-798.

and

Yáñez-Rivera B. and Brown J. (2015) Fireworms (Amphinomidae: Annelida) from Ascension and Saint Helena Island, Central South Atlantic Ocean. Marine Biodiversity Records 8, e149. doi: 10.1017/

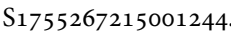

Correspondence should be addressed to: P. Brickle South Atlantic Environmental Research Institute, Stanley Cottage, Stanley, Falkland Islands, FIQQ 1 ZZ email: pbrickle@env.institute.ac.fk

Paul Brickle ${ }^{1,2,3}$, Judith Brown ${ }^{2,5}$, Frithjof C. Küpper ${ }^{4}$ and Paul E. Brewin ${ }^{1,2}$

${ }^{1}$ South Atlantic Environmental Research Institute, Stanley Cottage, Stanley, Falkland Islands, FIQQ 1ZZ, ${ }^{2}$ Shallow Marine Surveys Group, Stanley, Falkland Islands, FIQQ 1ZZ, ${ }^{3}$ School of Biological Sciences (Zoology), University of Aberdeen, Zoology Building, Tillydrone Avenue, Aberdeen $\mathrm{AB} 24$ 2TZ, UK, ${ }^{4}$ Oceanlab, University of Aberdeen, Main Street, Newburgh AB41 6AA, UK, ${ }^{5}$ Conservation \& Fisheries Department, Ascension Island Government, Ascension Island, ASCN 1 ZZ 